\title{
Anticandidal Activity of Omiganan and Its Retro Analog Alone and in Combination with Fluconazole
}

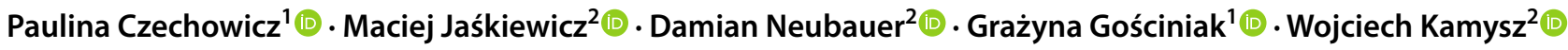

Accepted: 14 February 2021 / Published online: 2 March 2021

(c) The Author(s) 2021

\begin{abstract}
Vulvovaginal candidiasis (VVC) is a vaginal infection that manifests itself as several symptoms which can lead to various lifethreatening complications. The majority of VVC is caused by Candida albicans strains, and it is estimated that approximately $75 \%$ of women worldwide would suffer from this condition at least once during their lifetime. Surprisingly, the detailed pathomechanism of yeast-like fungi invasions in vagina is not yet fully understood. However, the ability to form biofilm on vaginal mucosa is considered as one of the critical factors associated with failure of the therapy and recurrences of the disease. Antimicrobial peptides (AMPs) are a promising class of compounds that are receiving a growing interest owing to their antibacterial, antifungal, and antibiofilm properties. Omiganan is a synthetic analog of Indolicidin that is characterized by wide spectrum of antimicrobial and antibiofilm activities. Recent reports suggest improved activity of analogs with a reversed sequence (retro-analog concept). Therefore, Omiganan and its retro analog were tested against planktonic forms and biofilm of 18 Candida strains isolated from VVC. Moreover, the synergy between the AMPs and fluconazole was studied as well. The AMPs appeared to be effective against $C$. albicans biofilm, and the reversion of the sequence generally led to an improved antimicrobial activity. Furthermore, confocal and scanning electron microscopic visualizations revealed the effectiveness of AMPs-fluconazole combinations also against fluconazole-resistant strains.
\end{abstract}

Keywords Antimicrobial peptides $\cdot$ Biofilm $\cdot$ Candida albicans $\cdot$ Fluconazole $\cdot$ Omiganan $\cdot$ Retro analogs $\cdot$ Vulvovaginal candidiasis

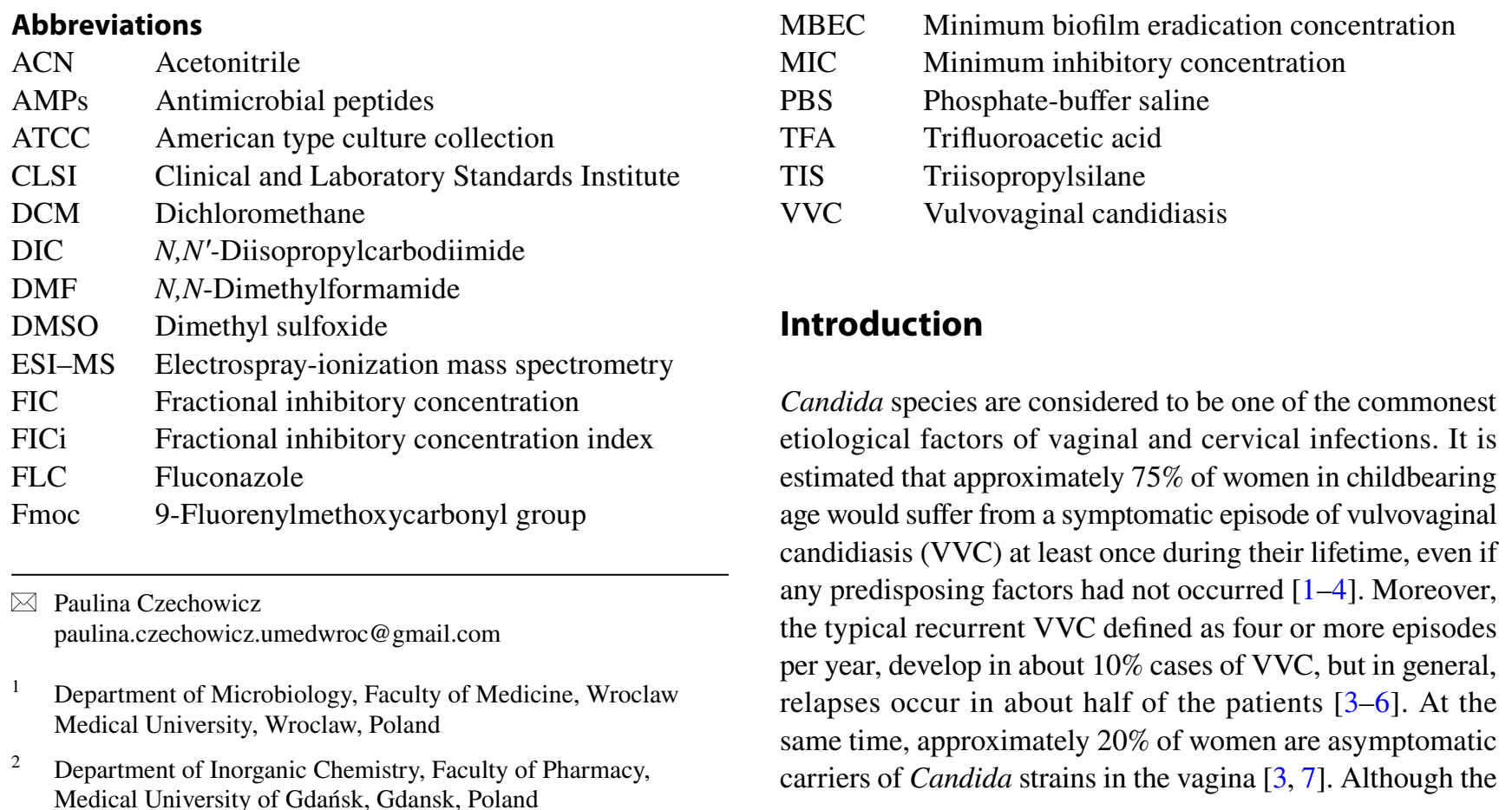


virulence factors of yeast-like fungi are quite well known, a detailed pathomechanism of vulvovaginal candidiasis still remain unclear [8]. Moreover, the role of potential factors enabling colonization and invasion of Candida, as well as specific recurrence tendencies, remain also unexplained [9]. Many authors suggest that the ability to form biofilm is essential for development of vaginal infections $[2,7,10]$. Meanwhile, the number of multidrug-resistant Candida strains has increased and conventional antifungals such as fluconazole (FLC) began to be inefficient. This particularly applies to fungi from the NCAC group (Non-C. albicans Candida) like $C$. glabrata and $C$. krusei. For this reason, methods of alternative therapy are constantly being sought. Among the compounds which are worth mentioning are those synthesized by bacteria, which are characterized by probiotic as well as antimicrobial activity, also against Candida. Among the microorganisms with probiotic antiCandida potential, there are mainly bacteria of the genus Lactobacillus, including L. acidophilus, L. rhamnosum, L. crispatus, L. fermentum, and L. brevis [11-16]. Besides their probiotic potential, these strains are characterized by production of variety antimicrobial compounds like organic acids, ethanol, enzymes, and hydrogen peroxide andantimicrobial peptides (AMPs) [17, 18]. The last one mentioned belongs to the promising and large group of compounds being a part of innate immune system of almost all organisms [19]. Apart from their wide-range of antimicrobial and immunomodulatory properties, some AMPs are characterized by unique antifungal as well as anti-biofilm activity [20]. Among these, a prominent representative is Omiganan, which is a synthetic analog of indolicidin - a peptide isolated from the cytoplasmic granules of bovine neutrophils [21]. This compound is characterized by a wide spectrum of antimicrobial activity, and it is one of AMPs that has lately passed the III phase of clinical trials [22]. To date, several studies reported possibility to use Omiganan against yeast-like fungi with promising results [21, 23-27]. However, there is a lack of research focused on its antibiofilm activity. In addition, recent studies indicate that its retro-analog (with reversed sequence) showed an improved activity against bacteria and fungi $[28,29]$. On the basis of this development, it has been postulated that both compounds (Omiganan and
retro-Omiganan) could effectively be used in the treatment of Candida infections associated with biofilm. Moreover, there are few studies that indicate synergistic anti-Candida effect of combination of azoles (e.g., fluconazole) with various AMPs [30-35]. This effect could probably be associated with different mechanisms of action of both groups of compounds. Regrettably, to date, Omiganan has not been investigated in this regard so far. The aim of this study was to learn whether or not Omiganan and its retro analog could be effective against planktonic forms and biofilm of clinical strains of $C$. albicans isolated from women with VVC. In addition, synergy with fluconazole has been tested.

\section{Materials and Methods}

\section{Peptide Synthesis}

Omiganan and retro-Omiganan (sequences in Table 1) were synthesized manually by solid-phase method using Fmoc chemistry on polystyrene Rink amide resin (Orpegen Peptide Chemicals GmbH, Heidelberg, Germany). Deprotection of the Fmoc group was performed with $20 \%$ (v/v) piperidine (Merck, Darmstadt, Germany) solution in DMF (Honeywell, Seelze, Germany) for $15 \mathrm{~min}$. Acylation was conducted in a DCM/DMF(1:1, v/v) solution with coupling reagents FmocAA-OH, OxymaPure, and DIC (mole ratio 1:1) for $1.5 \mathrm{~h}$ using a threefold molar excess. Every step was preceded by rinsing the resin and running the chloranil test. Peptides were cleaved from the resin using a mixture of TFA (Apollo Scientific, Denton, UK), TIS (Sigma-Aldrich, St. Louise, MO, USA), phenol (Sigma-Aldrich, St. Louise, MO, USA), and deionized water $(92.5: 2.5: 2.5: 2.5, \mathrm{v} / \mathrm{v} / \mathrm{v} / \mathrm{v})$. The cleavage was accomplished for $1.5 \mathrm{~h}$ with agitation. The peptides were purified by reversed-phase high-performance liquid chromatography, and their identity was confirmed by mass spectrometry (ESI-MS).

\section{Candida Strains and Microbiological Assay}

Microbiological assays were performed on 18 clinical strains of $C$. albicans acquired from the Internal Collection of the Department of Microbiology, Wroclaw Medical
Table 1 Peptides used in this study

\begin{tabular}{lllllll}
\hline Name & Sequence & Net charge & Average mass (Da) & \multicolumn{2}{l}{ MS analysis } \\
\cline { 5 - 7 } & & & & $\mathrm{z}$ & $\mathrm{m} / \mathrm{z}$ calc & $\mathrm{m} / \mathrm{z}$ found \\
\hline \multirow{2}{*}{ Omiganan } & \multirow{2}{*}{ ILRWPWWPWRRK-NH $_{2}$} & +5 & 1779.15 & 2 & 890.6 & 890.3 \\
& & & & 3 & 594.1 & 594.0 \\
& & & & 4 & 445.8 & 445.8 \\
retro-Omiganan & \multirow{2}{*}{ KRRWPWWPWRLI-NH } & & & 2 & 890.6 & 890.5 \\
& & & 3 & 594.1 & 594.1 \\
& & & 4 & 445.8 & 445.9
\end{tabular}


University. All analyzed strains were once originally isolated from vagina and cervix of women suffering from a fungal infection. Reference strain of C. albicans ATCC 10231 was obtained from the Polish Collection of Microorganisms (PCM, Polish Academy of Sciences, Wroclaw).

In the first step, Minimum Inhibitory Concentrations (MICs) of fluconazole (Merck, KGaA, Darmstadt, Germany), Omiganan, and retro-Omiganan were determined on 96-well polystyrene plates following microdilution method described by Clinical and Laboratory Standards Institute [36]. For this purpose, 24-h cultures of $C$. albicans from Sabouraud Dextrose Agar with chloramphenicol $(100 \mathrm{mg} / \mathrm{L})$ were transferred to sterile PBS (AppliChem GmBH, Darmstadt, Germany) to achieve a density of $0.5 \mathrm{McF}$ arland $\left(1-5 \times 10^{6}\right.$ cells per $\mathrm{mL}$ ). Then the suspension was diluted 1:1000 in RPMI 1640 medium (Merck, KGaA, Darmstadt, Germany). Working solutions of AMPs and fluconazole were prepared by dissolution in PBS and DMSO (Merck, KGaA, Darmstadt, Germany), respectively. Subsequently, the range of concentrations $(0.5-256 \mu \mathrm{g} /$ $\mathrm{mL}$ ) of test compounds was prepared and the inoculums were added $\left(1-5 \times 10^{3}\right.$ cells per $\left.\mathrm{mL}\right)$. All plates prepared in this way were then incubated for $24 \mathrm{~h}$ at $37^{\circ} \mathrm{C}$. For peptides, the MIC value was defined as a lowest concentration at which a noticeable growth of fungi was inhibited. For fluconazole, it was the concentration that inhibited at least $50 \%$ of yeast growth. Cell densities were determined spectrophotometrically at $530 \mathrm{~nm}$ (BiochromAsys UVM 340 Microplate Spectrophotometer, Biochrom Ltd, USA). Yeast growth was calculated based on the measured optical density (OD) at $530 \mathrm{~nm}$ using the following equation: $\left(\mathrm{OD}_{\text {well }}-\mathrm{OD}_{\text {background }}\right) /$ $\left(\mathrm{OD}_{\text {growth_control }}-\mathrm{OD}_{\text {background }}\right) \times 100 \%$. The procedure was conducted in triplicate and included growth and a sterility control.

\section{Activity Against Biofilm}

Minimum biofilm eradication concentrations (MBECs) were determined on 96-well polystyrene flat bottom plates with resazurin (7-hydroxy-3H-phenoxazin-3one 10-oxide) as a cell viability reagent [37]. For this purpose, the $0.5 \mathrm{McF}$ arland inoculum was diluted 1:100 (final concentration $1-5 \times 10^{4}$ cells per $\mathrm{mL}$ ) and $100 \mu \mathrm{L}$ of that suspension was added into the test plates. After $24 \mathrm{~h}$ of incubation at $37^{\circ} \mathrm{C}$, the wells of the plates were rinsed three times with phosphate buffer saline (PBS) to remove non-adherent cells. Subsequently, $100 \mu \mathrm{L}$ of the test compounds over a concentration range of 0.5-256 $\mu \mathrm{g} /$ $\mathrm{mL}$ were added to each well. After $24 \mathrm{~h}$ of incubation at $37{ }^{\circ} \mathrm{C}, 20 \mu \mathrm{L}$ of the resazurin solution $(4 \mathrm{mg} / \mathrm{mL})$ was added. The MBEC values were read out after $1 \mathrm{~h}$ of incubation at $37{ }^{\circ} \mathrm{C}$ with shaking $(120 \mathrm{rpm})$. The values were recorded as the lowest concentration at which the reduction of resazurin (from blue to pink) was lower or equal to $10 \pm 0.5 \%$ as compared to the positive $(100 \%)$ and negative (0\%) controls. All experiments were performed in triplicate and included growth and a sterility control.

\section{Fractional Inhibitory Concentration Index}

To study interactions between fluconazole and the peptides, fractional inhibitory concentration (FIC) index was determined, following the checkerboard method [38]. FIC index was calculated for the reference strain of $C$. albicans ATCC 10231 and for two randomly selected clinical strains by the lowest (number 18.) and the highest (number 13.) MIC values for fluconazole. For this purpose, serial dilutions of antimicrobial agents were prepared as previously for MIC determination. Horizontal wells were applied for fluconazole, while vertical ones for test of AMPs and the final concentrations range was $0.5-64 \mu \mathrm{g} / \mathrm{mL}$. Subsequently, the inoculum of the test strain was added, and the plates were incubated for $24 \mathrm{~h}$ at $37^{\circ} \mathrm{C}$. Inhibition of fungal growth was assessed visually. The following formula was used to calculate the FIC index:

$$
\begin{aligned}
& \frac{A}{\mathrm{MICA}}+\frac{B}{\mathrm{MICB}}=\mathrm{FIC}_{\mathrm{A}}+\mathrm{FIC}_{\mathrm{B}}=\text { FICindex, } \\
& \text { average } \Sigma \mathrm{FIC}=\frac{\sum \mathrm{FIC}}{n}
\end{aligned}
$$

where $A$ and $B$ are inhibitory concentrations of the agents determined by the checkerboard method. MIC values were determined previously (individual compounds) and $\mathrm{FIC}_{A}$ and FIC $_{B}$ were the ratio of the two values; $n$ is the number of FIC indices. The FIC index values were interpreted according to EUCAST guidelines [39]. The results are shown in Table 2. The experiments were performed in duplicate for each strain.

\section{Microscopic Assay}

Visualization of the results was carried out for selected strains, namely, those nos. 13 and 18 using confocal microscopy and scanning electron microscopy (SEM). The microscopy was carried out in the Laboratory of Electron Microscopy of the University of Life Sciences in Wroclaw.

Table 2 Correlation between FIC and the effect of the combination of antimicrobial agents

\begin{tabular}{ll}
\hline FIC index & Effect \\
\hline$\leq 0.5$ & Synergy \\
$>0.5$ to 1.0 & Additive \\
$>1.0$ to $\leq 2.0$ & Indifference \\
$>2.0$ & Antagonism \\
\hline
\end{tabular}




\section{Confocal Microscopy}

Samples of biofilms of both selected strains (nos. 13 and 18) and the reference strain of C. albicans ATCC 10231 were prepared directly on coverslips. Culture preparation and biofilm growth were carried out in the same way as that described for MBEC determination. For this purpose, the 24-h mature biofilms were exposed to fluconazole, Omiganan and retro-Omiganan at MBEC concentrations and two combinations of fluconazole with Omiganan or retro-Omiganan. Concentrations of combinations of the compounds were selected based on FIC values with $8 \mu \mathrm{g} /$ $\mathrm{mL}$ of fluconazole and $4 \mu \mathrm{g} / \mathrm{mL}$ of each peptide. For this combination FIC values did not exceed 0.5 and can be interpreted as synergy of both compounds. After 24-h incubation at $37^{\circ} \mathrm{C}$, the LIVE/DEAD BacLight Bacterial Viability Kit (Thermo Fisher Scientific, Waltham, MA, USA) was added to stain biofilms for $30 \mathrm{~min}$ in the dark. SYTO $^{\text {TM }} 9$ (excitation wavelength $488 \mathrm{~nm}$ ) was taken up by live fungal cells (green), while propidium iodide (excitation wavelength $532 \mathrm{~nm}$ ) stained only dead cells (red). Negative control involved coverslips that were exposed to UV lamp for $30 \mathrm{~min}$. All samples were viewed under a LeicaDMi8 confocal microscope at a $630 \times$ magnification.

\section{Scanning Electron Microscopy}

Biofilm samples prepared in 8-well plates were fixed with 2.5\% glutaraldehyde (Argenta, Poland). Further cell fixation was followed by incubation in $10 \%$ formalin (Argenta) and dehydration in increasing concentrations $(20,40,60,80,95$, and $100 \%$ ) of ethanol (Argenta) for 1 min each step. Finally, the samples were incubatedfor $1 \mathrm{~min}$ in acetone (Argenta). The dried samples were affixed to SEM stubs and placed into a gold/palladium sputter coater. The specimens were viewed at $\times 1500-5000$ magnification in a ZEISS EVOL515 scanning electron microscope.

\section{Results}

\section{Minimum Inhibitory Concentration}

All tested compounds exhibited an antimicrobial activity against reference and clinical strains of $C$. albicans (Table 3).

MIC values of fluconazole for the vast majority of the tested strains did not exceed $4 \mu \mathrm{g} / \mathrm{mL}$ (except strain nos. 8 and 13), and the commonest value was $0.125 \mu \mathrm{g} / \mathrm{mL}$. Moreover, only one $C$. albicans strain appeared to be highly resistant with a MIC value above $64 \mu \mathrm{g} / \mathrm{mL}$. Interestingly, strains less sensitive to fluconazole were more susceptible to peptides. MIC value distribution of the compounds against clinical strains of $C$. albicans strains is presented in Fig. 1.
Table 3 MIC values $(\mu \mathrm{g} / \mathrm{mL})$ of fluconazole, Omiganan and its retro analog against clinical strains of $C$. albicans isolated from VVC and reference $C$. albicans ATCC 10231

\begin{tabular}{llll}
\hline Strain no & \multicolumn{3}{c}{ MIC $(\mu \mathrm{g} / \mathrm{mL})$} \\
\cline { 2 - 4 } & Fluconazole & Omiganan & $\begin{array}{l}\text { Retro- } \\
\text { Omiganan }\end{array}$ \\
\hline 1 & 0.5 & 128 & 32 \\
2 & 0.125 & 64 & 32 \\
3 & 0.125 & 128 & 32 \\
4 & 0.25 & 128 & 64 \\
5 & 0.25 & 128 & 32 \\
6 & 0.125 & 64 & 32 \\
7 & 0.125 & 128 & 64 \\
8 & 16 & 64 & 32 \\
9 & 0.125 & 128 & 32 \\
10 & 0.125 & 64 & 32 \\
11 & 0.125 & 64 & 32 \\
12 & 0.25 & 64 & 32 \\
13 & 256 & 64 & 32 \\
14 & 0.125 & 64 & 32 \\
15 & 4 & 256 & 128 \\
16 & 0.125 & 128 & 32 \\
17 & 0.125 & 128 & 64 \\
18 & 0.125 & 64 & 32 \\
C. albicans & 1 & 128 & 32 \\
ATCC 10231 & & & \\
\hline
\end{tabular}

MIC values of Omiganan ranged from 64 to $256 \mu \mathrm{g} / \mathrm{mL}$, while the concentration of $64 \mu \mathrm{g} / \mathrm{mL}$ was the commonest value (9/18 strains). In the case of retro-Omiganan, MIC values ranged between 32 and $128 \mu \mathrm{g} / \mathrm{mL}$, one being that of $32 \mu \mathrm{g} / \mathrm{mL}$ (in 14 strains out of 18 tested). To evaluate peptides selectivity, the results of our previous study on cytotoxicity against $\mathrm{HaCaT}$ cell line (immortalized human keratinocytes) were included in calculations of SI indices (Table 4) [29]. The geometric mean (GM) of the MIC values against $C$. albicans was calculated. $\mathrm{SI}$ is the $\mathrm{IC}_{50}$ to $\mathrm{GM}$ ratio.

\section{Minimum Biofilm Eradication Concentration}

In Table 5, minimum biofilm eradication concentration (MBEC) values of fluconazole and the tested peptides against reference and clinical Candida strains are presented.

MBEC values of the azole attained a top value of $512 \mu \mathrm{g} / \mathrm{mL}$, while MBEC ones of the two AMPs were at most twice as high as the corresponding MIC value. MBEC distribution of fluconazole and peptides against that of clinical C. albicans strains used in this study is displayed in Fig. 2. 
Fig. 1 MIC values distribution of fluconazole and the AMPs

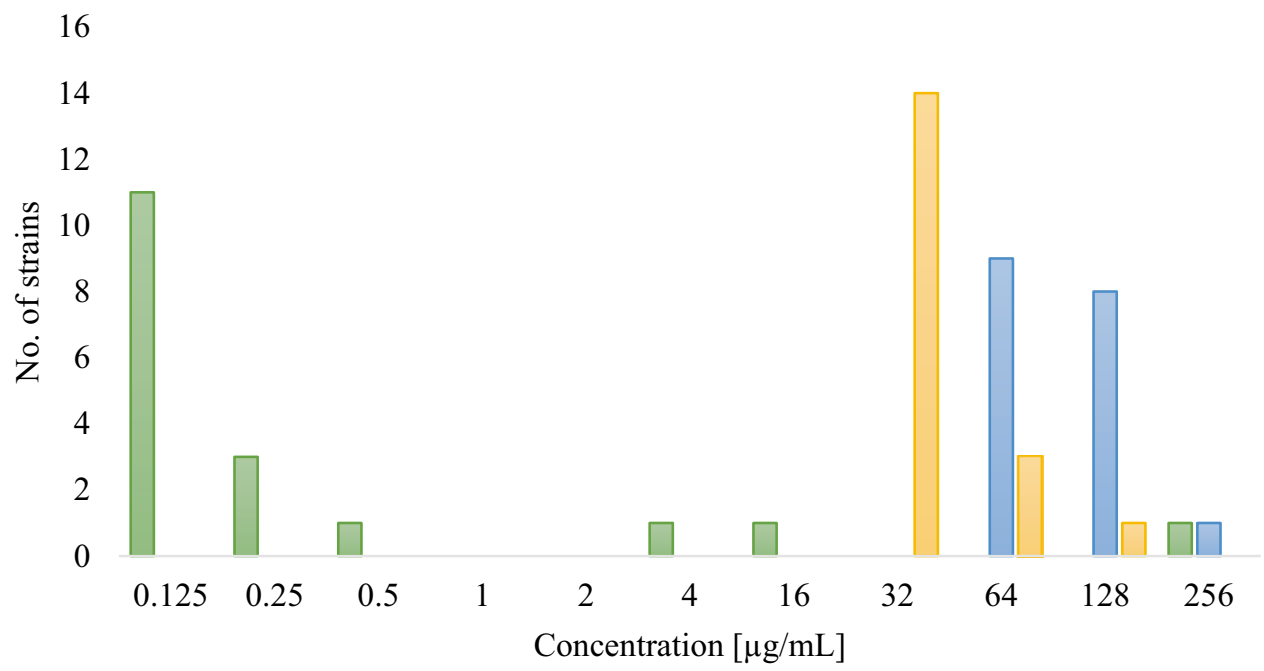

$\square$ Fluconaozle $\square$ Omiganan $\square$ retro-Omiganan

The MBEC values of Omiganan ranged from 128 to $512 \mu \mathrm{g} / \mathrm{mL}$ and most often were $256 \mu \mathrm{g} / \mathrm{mL}$ (for 16 of 18 strains). With retro-Omiganan MBEC values ranged between 64 and $256 \mu \mathrm{g} / \mathrm{mL}$, with the top one of $128 \mu \mathrm{g} / \mathrm{mL}(10 / 18$ strains).

\section{FIC Index}

The FIC index values reveal an additive effect of AMPs and fluconazole combinations (FICi $0.5-1$ ) against planktonic forms of $C$. albicans in concentrations up to 8 times lower than when using each of the compounds separately. The FICi for Omiganan and fluconazole slightly exceeded 0.5 for both the reference strain ATCC 10231 and the C. albicans strain which was resistant to fluconazole (no. 13), reaching a value of 0.578 . Interestingly, for the randomly selected strain susceptible to fluconazole (no. 18), FIC index of 4.125 indicated antagonism. FIC indices of retro-Omiganan combined with fluconazole were 0.780 and 0.687 for $C$. albicans ATCC 10231 and FLC-resistant strain, respectively. Similarly, FIC index for the susceptible to azole strain was 4.133 indicating antagonism of both compounds as well (Table 6).

Confocal fluorescence micrographs of the AMPs and fluconazole treated Candida biofilm are presented in Fig. 3.

Table 4 IC50, GM, and selectivity indices (SI) of the AMPs determined for clinical strains of $C$. albicans

\begin{tabular}{llll}
\hline Peptide & GM & $\begin{array}{l}\text { IC }_{50} \\
\text { Jaśkiewicz et al. } \\
{[29]}\end{array}$ & SI \\
\hline Omiganan & 94.06 & 79.39 & 0.84 \\
Retro-Omiganan & 38.79 & 29.51 & 0.76 \\
\hline
\end{tabular}

In confocal microscopy, the biomass of Candida biofilm treated with test compounds in concentrations equal to the respective MBEC and FIC values $(8 \mu \mathrm{g} / \mathrm{mL}$ of fluconazole and $4 \mu \mathrm{g} / \mathrm{mL}$ of each peptide) was almost completely eradicated. Uptake of PI (red fluorescence) is the result of the increased

Table 5 MBEC values $(\mu \mathrm{g} / \mathrm{mL})$ of the fluconazole, Omiganan and its retro analog against clinical strains of $C$. albicans isolated from VVC and reference $C$. albicans ATCC 10231. GM determined for clinical strains is included

\begin{tabular}{|c|c|c|c|}
\hline \multirow[t]{2}{*}{ Strain no } & \multicolumn{3}{|c|}{$\operatorname{MBEC}(\mu \mathrm{g} / \mathrm{mL})$} \\
\hline & Fluconazole & Omiganan & Retro-Omiganan \\
\hline 1 & 512 & 256 & 64 \\
\hline 2 & 512 & 256 & 128 \\
\hline 3 & 512 & 256 & 128 \\
\hline 4 & 512 & 256 & 256 \\
\hline 5 & 512 & 256 & 128 \\
\hline 6 & 512 & 256 & 64 \\
\hline 7 & 512 & 512 & 128 \\
\hline 8 & 256 & 256 & 64 \\
\hline 9 & 512 & 256 & 128 \\
\hline 10 & 512 & 256 & 128 \\
\hline 11 & 512 & 256 & 64 \\
\hline 12 & 512 & 128 & 64 \\
\hline 13 & 512 & 256 & 64 \\
\hline 14 & 512 & 256 & 128 \\
\hline 15 & 512 & 256 & 128 \\
\hline 16 & 512 & 256 & 128 \\
\hline 17 & 512 & 256 & 128 \\
\hline 18 & 512 & 256 & 64 \\
\hline GM & 492.66 & 256.00 & 101.59 \\
\hline $\begin{array}{l}\text { C. albicans } \\
\text { ATCC } 10231\end{array}$ & 512 & 256 & 64 \\
\hline
\end{tabular}


Fig. 2 MBEC distribution of fluconazole and tested AMPs

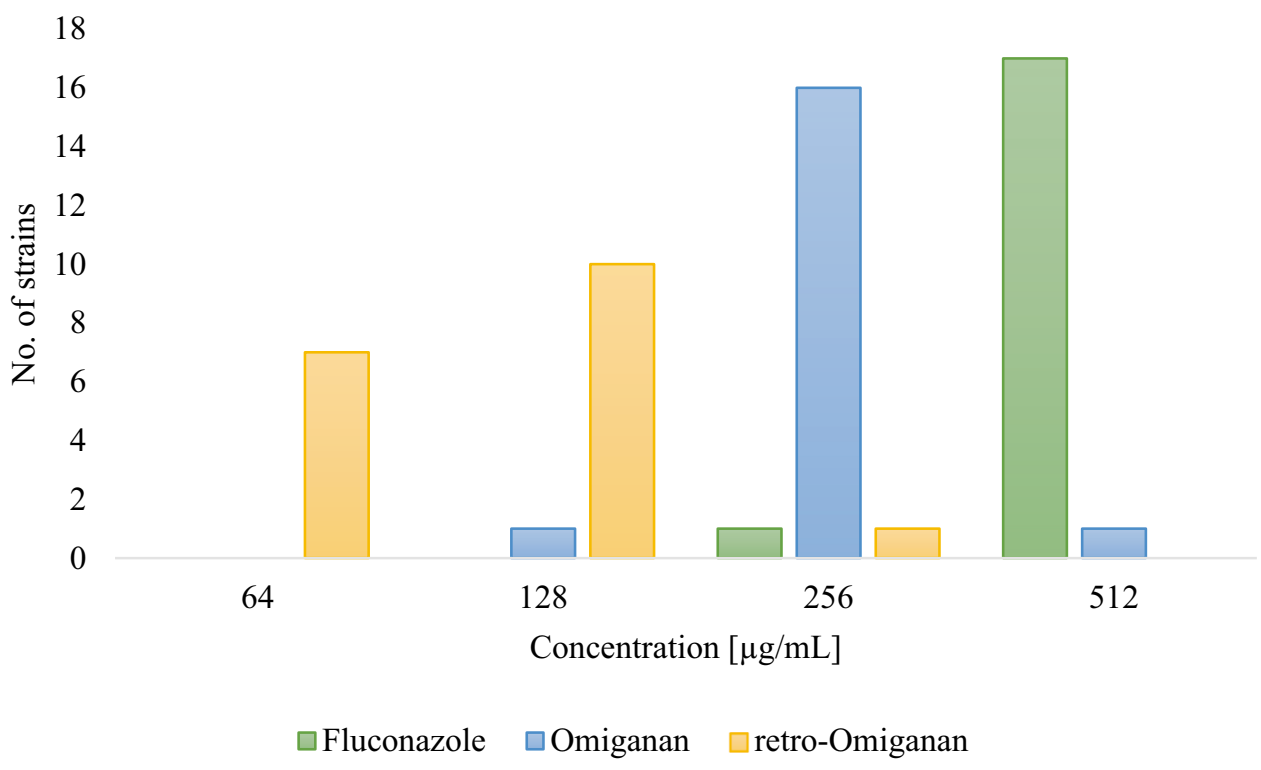

membrane permeability indicating cell death. Figure 3 a. and $\mathrm{b}$ represent positive (untreated biofilm) and negative control (biofilm exposed to UV radiation) respectively. Evidently biofilm consists of blastospores and elongated filaments. On micrographs 3.C., 3.D., and 3.E. there are biofilms treated with the compounds at MBEC concentrations (fluconazole, Omiganan, retro-Omiganan, respectively). Reduction in biofilm biomass is seen, but among few surviving cells, the majority is recognized as dead blastospores (stained red). Similar effect was noticed with combinations. In this case, almost all biofilms were eradicated, and the remaining cells were mostly dead. Surprisingly, confocal microscopy revealed that combinations of Omiganan and retro-Omiganan with fluconazole were also effective in strain no. 18 for which FICi value indicated antagonism.

Scanning electron microscopy has also shown that, apart from the reduction of biofilm biomass, blastospores are seen among the few surviving cells in the presence of the tested compounds (in MBEC and FIC concentrations) and no filamentation occurs (Fig. 4). Figure 4 a represents a positive control (untreated biofilm) in which multiple blastospores clusters and single hyphae are noticed. Treatment with MBEC concentrations of fluconazole and retro-Omiganan

Table 6 FIC index values of combination of fluconazole with Omiganan and retro-Omiganan against $C$. albicans ATCC 10231 reference strain and two clinical $C$. albicans strains isolated from VVC

\begin{tabular}{lll}
\hline & $\begin{array}{l}\text { Omiganan }+ \\
\text { fluconazole }\end{array}$ & $\begin{array}{l}\text { retro-Omiganan }+ \\
\text { fluconazole }\end{array}$ \\
\hline C. albicans ATCC 10231 & 0.578 & 0.780 \\
Strain no. 13 & 0.578 & 0.687 \\
Strain no. 18 & 4.125 & 4.133 \\
\hline
\end{tabular}

(4.B. and 4.D.) resulted in reduction of biofilm with single filaments and few blastospores surviving. Unfortunately, Omiganan at MBEC concentration failed to eradicate biofilm (Fig. 4c) as indicated by blastospores remaining in clusters. Concentrations equal to the FIC values $(8 \mu \mathrm{g} / \mathrm{mL}$ of fluconazole and $4 \mu \mathrm{g} / \mathrm{mL}$ of each peptide) were almost as effective in biofilm eradication as MBEC values with reduction in biofilm biomass with no filamentation.

\section{Discussion}

Vulvovaginal candidiasis remains the second commonest gynecological infection in women worldwide, significantly reducing their life quality and comfort [3, 40, 41]. Although an increasing percentage of VVC infections is caused by species belonging to the NCAC group, which are resistant to the classic treatment regimen, $C$. albicans remains the major etiologic factor of fungal vaginitis $[2,5,7,10]$. It was speculated that therapeutic failures during the empirical use of azoles - mainly fluconazole - were associated with an increasing resistance of $C$. albicans strains against this group of antimycotics. Meanwhile, vaginal yeasts that were isolated in clinical practice tend to be susceptible to fluconazole [1, 5, 42-44]. This fact may provide an argument to the hypothesis that the formation of a highly resistant and impermeable biofilm on the vaginal mucosa by Candida species is responsible for the lack of therapeutic effect of using azoles $[2,5,7,8,10,40,41]$. Hence, intensive search for alternative therapies in the treatment of fungal infections (including VVC) focuses, among others, on testing compounds that can potentially be active against biofilm. For instance, AMPs are the compounds with antimicrobial and antibiofilm potential and Omiganan is one of the extensively 
Fig. 3 Confocal fluorescence microscopy images of Candida biofilm. a Untreated biofilm, and biofilm treated with b UV radiation, $\mathbf{c}$ fluconazole, $\mathbf{d}$ Omiganan, e Retro-Omiganan, $\mathbf{f}$ combination of fluconazole and Omiganan, and $\mathbf{g}$ combination of fluconazole and retroOmiganan

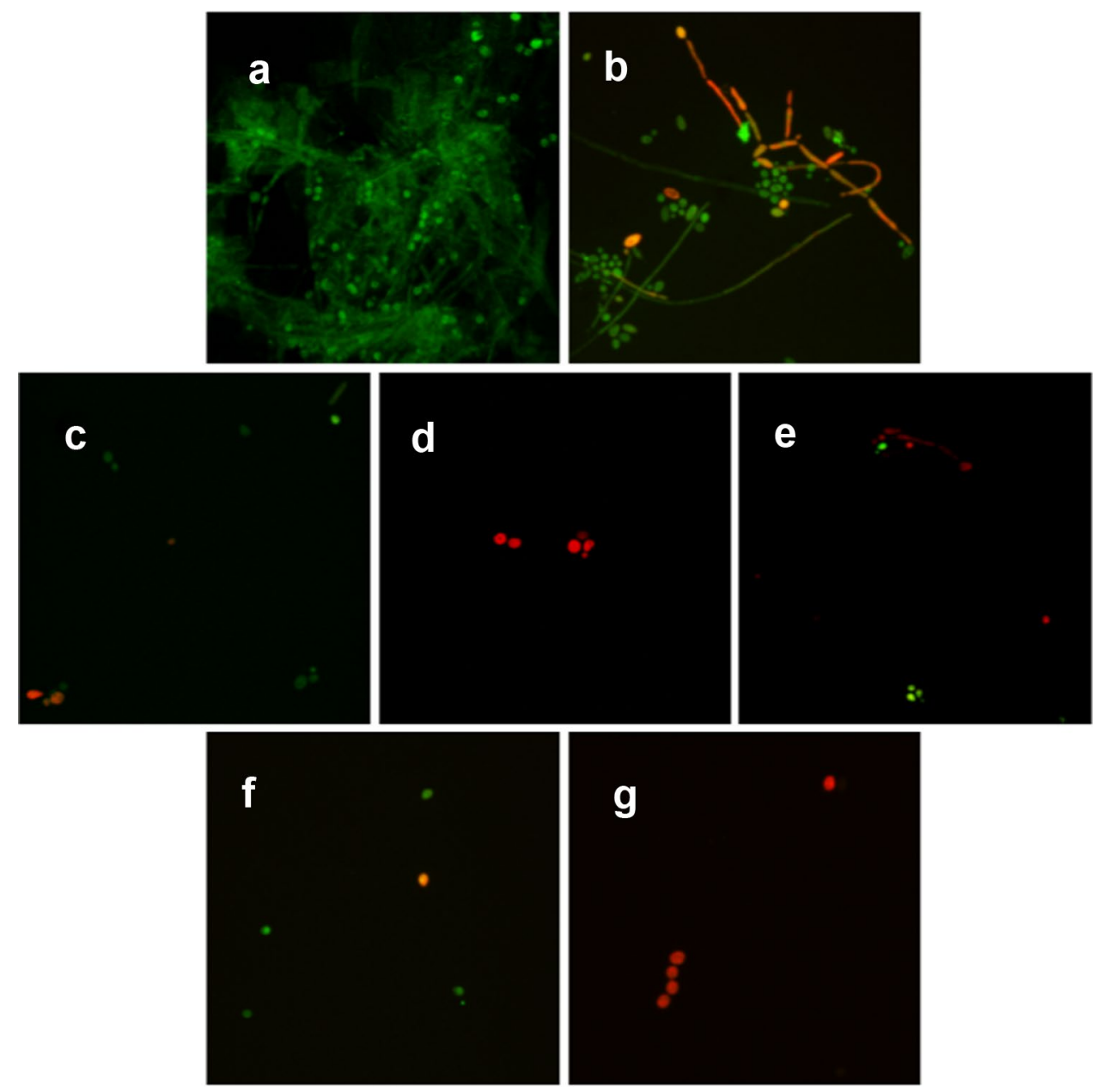

studied [29, 45]. A recently published report on enhancement of antimicrobial activity of selected AMPs indicate that reversion of Omiganan sequence results in enhanced activity against microorganisms with a slight contribution of hemolysis [28]. Accordingly, the aim of this study was to determine, whether or not the effect would have been observed in the case of clinical strains of Candida isolated from VVC. For this purpose, evaluation of the antimicrobial activity was conducted against both the planktonic form and biofilm. The obtained MIC values for Omiganan and its retro analog against 18 clinical and one reference strain of $C$. albicans ATCC 10231 confirmed the hypothesis [28]. Moreover, the amino acid sequence reversion resulted in a distinctly increased antifungal activity. Geometric mean of MIC values of Omiganan was substantially higher (94.06) than that of the retro analog (38.79). A similar effect was achieved with regard to the biofilm structure formed by the strains. MBEC values of both AMPs were twice and four times as high as the corresponding MIC values. GMs of MBEC values for Omiganan and retro-Omiganan were 256.00 and 101.59, respectively. Considering MIC values and $\mathrm{IC}_{50}$ against $\mathrm{HaCaT}$ cell line determined by our group in the previous study [28], it seemed worthwhile to estimate selectivity indices (Table 4). Those for Omiganan and its retro analog are similar amounting to 0.84 and 0.76 , respectively. Interesting results were obtained during a pilot study on the effect of the fluconazole-peptide combination against $C$. albicans. For both, the reference strain and the only fluconazole-resistant strain among the tested strains, the FICi values indicate either a synergistic or an additive effect of the combination of azole with Omiganan or its retro analog - in concentrations many times lower than the corresponding MIC values. Meanwhile, with the strain susceptible to fluconazole, the result was opposite, indicating antagonism of both azole-AMP pairs. Despite this small group of the analyzed strains, it was decided to verify the results using confocal microscopy and scanning electron microscopy. Microscopic analyses confirmed the finding that using combinations of fluconazole with peptides at concentrations determined by the checkerboard assay resulted in eradication of fungal biofilm. Few cells remaining in the field of view were dead (as visualized by LIVE/DEAD staining) and filamentation did not appear (Figs. 3 and 4). Perhaps this phenomenon is caused by different mechanisms 

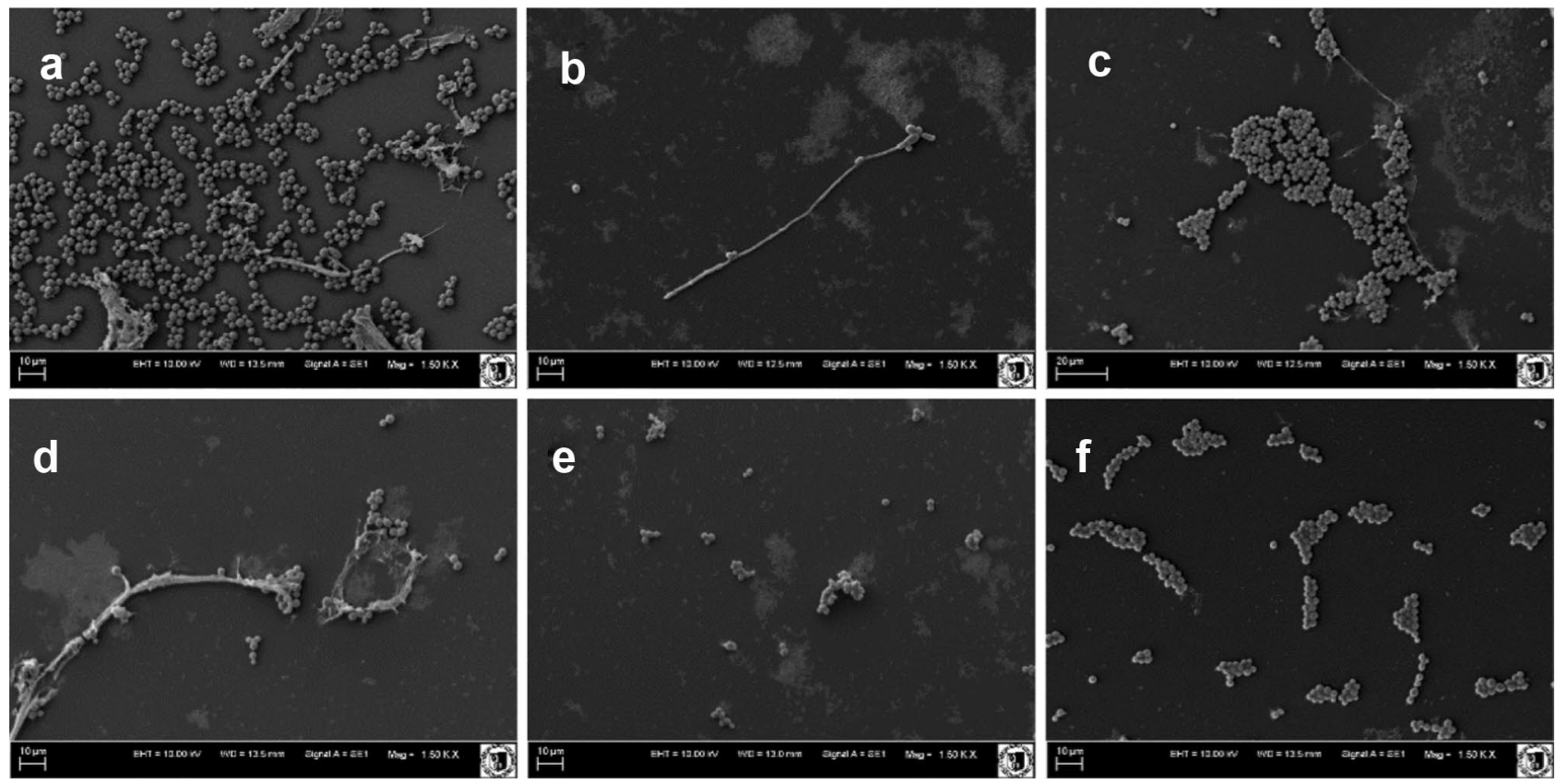

Fig. 4 Scanning electron microscopy images of Candida biofilm - a Untreated biofilm, and biofilm treated with b Fluconazole, $\mathbf{c}$ Omiganan, $\mathbf{d}$ Retro-Omiganan, e combination of fluconazole and Omiganan, and $\mathbf{f}$ Combination of fluconazole and retro-Omiganan

of action of both groups of compounds. It is well known that molecular target of fluconazole is Erg11 enzyme $(14 \alpha$-lanosterol demethylase), which is involved in the synthesis of ergosterol. Under the influence of fluconazole, a change occurs in the composition of the cell membrane, its liquefaction and an increase in permeability to $\mathrm{K}^{+}$and ATP ions, which results in a fungistatic effect [46]. In contrast, Omiganan and retro-Omiganan interact directly with the cell membrane leading to its permeabilization and cell death. Hypothetically, the permeabilization of membranes by AMPs can support the penetration of fluconazole into its intracellular molecular target. Fluconazole also affects the structure of the cell membrane, thus facilitating its permeabilization by AMPs. Similar, although not yet understood, synergistic or additive effects of fluconazole with various AMPs against Candida spp. strains (especially FLC-resistant fungi) were reported [30-35]. It was claimed that combination of different compounds as described above could be one of the most promising approach as to develop alternative therapy against multidrug resistant or biofilmforming yeast-like fungi. The results obtained in this study remain only a highly optimistic and promising premise and may constitute a starting point for further research on the effects of both Omiganan and its retro analog on Candida yeast-like fungi. Due to the limited number of the strains tested, the results require verification on a larger pool of Candida isolates, which also includes strains from the NCAC group. In the course of further work, it would undoubtedly be worthwhile to determine the toxicity of Omiganan and its retro analog to human cell lines. Cytotoxicity studies should include compounds (fluconazole and peptides) alone and combined (according to FICi values) to learn how specific combinations with synergistic activity determined in this study affect normal human cells. Cytotoxicity of AMPs seems to be a serious drawback and further studies on the proposed combination of antimicrobial agents can shed the light on this important issue. Beneficial effect can be expected owing to a considerably lower effective concentration of AMPs when combined with fluconazole.

\section{Conclusions}

Preliminary results of our study, as the first or one of first research of this kind, indicate antimicrobial activity of Omiganan and its newly synthesized retro analog against clinical strains of yeast-like fungi Candida isolated from women with VVC. Despite a small pool of investigated strains, there is a tendency indicating higher anticandidal activity of retro-Omiganan than the parent peptide - both against planktonic cells as well as biofilm. The promising results were noticed in the case of synergy studies. For both compounds, a potential synergistic effect in combination with conventionally used fluconazole was indicated. However, there is a need to confirm our findings in further studies on a wider range of clinical strains. This may lead for application of a well-known antimycotic and 
peptides in combination therapy in concentrations much lower than when used separately - non-toxic to eukaryotic cells, and therefore safer.

Author Contribution The manuscript was written through contributions of all authors. All authors have given approval to the final version of the manuscript.

Funding This research was financially supported by the Ministry of Health subvention according to number of SUB.A130.19.021 from the IT Simple system of Wroclaw Medical University, and the synthesis of peptides in this study was financially supported by the Medical University of Gdansk (statutory grant no. ST-02-0087/07/508).

Data Availability All data generated or analyzed during this study are included in this published article.

\section{Declarations}

Research Involving Human Participants and/or Animals The article does not contain any studies in patients by any of the authors. This article does not contain studies with human or animal subjects performed by any of the authors that should have been approved by Ethics Committee.

Conflict of Interest The authors declare that they have no competing interests.

Open Access This article is licensed under a Creative Commons Attribution 4.0 International License, which permits use, sharing, adaptation, distribution and reproduction in any medium or format, as long as you give appropriate credit to the original author(s) and the source, provide a link to the Creative Commons licence, and indicate if changes were made. The images or other third party material in this article are included in the article's Creative Commons licence, unless indicated otherwise in a credit line to the material. If material is not included in the article's Creative Commons licence and your intended use is not permitted by statutory regulation or exceeds the permitted use, you will need to obtain permission directly from the copyright holder. To view a copy of this licence, visit http://creativecommons.org/licenses/by/4.0/.

\section{References}

1. Tomaszewski J (2011) The statement of polish gynecological society experts on the etiology and treatment of recurrent vulvovaginal candidiasis. Ginekol Pol 82:869-873

2. Harriott MM, Lilly EA, Rodriguez TE et al (2010) Candida albicans forms biofilms on the vaginal mucosa. Microbiology 156:3635-3644. https://doi.org/10.1099/mic.0.039354-0

3. Gonçalves B, Ferreira C, Alves CT et al (2016) Vulvovaginal candidiasis: epidemiology, microbiology and risk factors. Crit Rev Microbiol 42:905-927. https://doi.org/10.3109/1040841X.2015.1091805

4. Sobel JD (2007) Vulvovaginal candidosis. Lancet 369:1961-1971. https://doi.org/10.1016/S0140-6736(07)60917-9

5. Hacioglu M, Guzel CB, Savage PB, Seher Birteksoz Tan A (2019) Antifungal susceptibilities, in vitro production of virulence factors and activities of ceragenins against Candida spp. isolated from vulvovaginal candidiasis. Med Mycol 57:291-299. https://doi. org/10.1093/mmy/myy023
6. Brandolt TM, Klafke GB, Gonçalves CV et al (2017) Prevalence of Candida spp. in cervical-vaginal samples and the in vitro susceptibility of isolates. Brazilian J Microbiol 48:145-150. https:// doi.org/10.1016/j.bjm.2016.09.006

7. Muzny CA, Schwebke JR (2015) Biofilms: an underappreciated mechanism of treatment failure and recurrence in vaginal infections. Clin Infect Dis 61:601-606. https://doi.org/10.1093/cid/civ353

8. Rodríguez-Cerdeira C, Gregorio MC, Molares-Vila A et al (2019) Biofilms and vulvovaginal candidiasis. Colloids Surfaces B Biointerfaces 174:110-125. https://doi.org/10.1016/j.colsurfb. 2018.11.011

9. Swidsinski A, Guschin A, Tang Q et al (2019) Vulvovaginal candidiasis: histologic lesions are primarily polymicrobial and invasive and do not contain biofilms. Am J Obstet Gynecol 220:91.e1-91.e8. https://doi.org/10.1016/j.ajog.2018.10.023

10. Paiva LCF, Vidigal PG, Donatti L et al (2012) Assessment of in vitro biofilm formation by Candida species isolates from vulvovaginal candidiasis and ultrastructural characteristics. Micron 43:497-502. https://doi.org/10.1016/j.micron.2011.09.013

11. Aarti C, Khusro A, Varghese R et al (2017) In vitro studies on probiotic and antioxidant properties of Lactobacillus brevis strain LAP2 isolated from Hentak, a fermented fish product of North-East India. LWT - Food Sci Technol 86:438-446. https:// doi.org/10.1016/j.lwt.2017.07.055

12. Kang $\mathrm{CH}$, Han $\mathrm{SH}$, Kim YG et al (2018) In vitro probiotic properties of Lactobacillus salivarius MG242 isolated from human vagina. Probiotics Antimicrob Proteins 10:343-349. https://doi.org/10.1007/s12602-017-9323-5

13. Kumherová M, Veselá K, Kosová M et al (2020) Novel potential probiotic Lactobacilli for prevention and treatment of vulvovaginal infections. Probiotics Antimicrob Proteins. https:// doi.org/10.1007/s12602-020-09675-2

14. Kovachev SM, Vatcheva-Dobrevska RS (2014) Local probiotic therapy for vaginal Candida albicans infections. Probiotics Antimicrob Proteins 7:38-44. https://doi.org/10.1007/s12602-014-9176-0

15. Ouarabi L, Chait YA, Seddik HA et al (2019) Newly isolated Lactobacilli strains from algerian human vaginal microbiota: Lactobacillus fermentum strains relevant probiotic's candidates. Probiotics Antimicrob Proteins 11:43-54. https://doi. org/10.1007/s 12602-017-9360-0

16. Lakhtin M, Alyoshkin V, Lakhtin V et al (2010) Probiotic Lactobacillus and Bifidobacterial lectins against Candida albicans and Staphylococcus aureus clinical strains: new class of the pathogen biofilm destructors. Probiotics Antimicrob Proteins 2:186-196. https://doi.org/10.1007/s12602-010-9046-3

17. Hassan M, Kjos M, Nes IF et al (2012) Natural antimicrobial peptides from bacteria: characteristics and potential applications to fight against antibiotic resistance. J Appl Microbiol 113:723736. https://doi.org/10.1111/j.1365-2672.2012.05338.x

18. Reis JA, Paula AT, Casarotti SN, Penna ALB (2012) Lactic acid bacteria antimicrobial compounds: characteristics and applications. Food Eng Rev 4:124-140. https://doi.org/10.1007/ s12393-012-9051-2

19. Mansour SC, Pena OM, Hancock RE (2014) Host defense peptides: front-line immunomodulators. Trends Immunol 35:443450. https://doi.org/10.1016/j.it.2014.07.004

20. Dawgul M, Barańska-Rybak W, Bielińska S et al (2010) Wpływ peptydów przeciwdrobnoustrojowych na biofilm Candida. Alerg Astma Immunol 15:220-225

21. Sader HS, Fedler KA, Rennie RP et al (2004) Omiganan pentahydrochloride (MBI 226), a topical 12-amino-acid cationic peptide: spectrum of antimicrobial activity and measurements of bactericidal activity. Antimicrob Agents Chemother 48:31123118. https://doi.org/10.1128/AAC.48.8.3112-3118.2004

22. Mookherjee N, Anderson MA, Haagsman HP, Davidson DJ (2020) Antimicrobial host defence peptides: functions and 
clinical potential. Nat Rev Drug Discov 19:311-332. https://doi. org/10.1038/s41573-019-0058-8

23. Rubinchik E, Dugourd D, Algara T et al (2009) Antimicrobial and antifungal activities of a novel cationic antimicrobial peptide, omiganan, in experimental skin colonisation models. Int J Antimicrob Agents 34:457-461. https://doi.org/10.1016/j.ijantimicag. 2009.05.003

24. Fritsche TR, Rhomberg PR, Sader HS, Jones RN (2008) Antimicrobial activity of omiganan pentahydrochloride against contemporary fungal pathogens responsible for catheterassociated infections. Antimicrob Agents Chemother 52:11871189. https://doi.org/10.1128/AAC.01475-07

25. Kamysz W, Nadolski P, Kedzia A, et al In vitro activity of synthetic antimicrobial peptides against Candida. In: Polish J Microbiol

26. Ng SMS, Yap YYA, Cheong JWD et al (2017) Antifungal peptides: a potential new class of antifungals for treating vulvovaginal candidiasis caused by fluconazole-resistant Candida albicans. J Pept Sci 23:215-221. https://doi.org/10.1002/psc.2970

27. Durnaœ B, Wnorowska U, Pogoda K et al (2016) Candidacidal activity of selected ceragenins and human cathelicidin LL-37 in experimental settings mimicking infection sites. PLoS ONE 11:1-20. https://doi.org/10.1371/journal.pone.0157242

28. Neubauer D, Jaśkiewicz M, Migoń D et al (2017) Retro analog concept: comparative study on physico-chemical and biological properties of selected antimicrobial peptides. Amino Acids. https:// doi.org/10.1007/s00726-017-2473-7

29. Jaśkiewicz M, Neubauer D, Kazor K et al (2019) Antimicrobial activity of selected antimicrobial peptides against planktonic culture and biofilm of Acinetobacter baumannii. Probiotics Antimicrob Proteins 11:317-324. https://doi.org/10.1007/s12602-018-9444-5

30. Sun W, Zhang L, Lu X, et al Ras / cAMP / PKA signalling pathway and virulence

31. Taveira GB, Carvalho AO, Rodrigues R et al (2016) Thioninlike peptide from Capsicum annuum fruits: mechanism of action and synergism with fluconazole against Candida species Applied microbiology. BMC Microbiol 16:1-13. https://doi.org/10.1186/ s12866-016-0626-6

32. de Aguiar FLL, Cavalcante C, dos Santos Fontenelle RO, et al (2020) The antiproliferative peptide $\mathrm{Ctn}[15-34]$ is active against multidrugresistant yeasts Candida albicans and Cryptococcus neoformans

33. Maurya IK, Thota CK, Sharma J et al (2013) Mechanism of action of novel synthetic dodecapeptides against Candida albicans. Biochim Biophys Acta - Gen Subj 1830:5193-5203. https://doi. org/10.1016/j.bbagen.2013.07.016

34. Mora-Navarro C, Caraballo-Leõn J, Torres-Lugo M, OrtizBermúdez P (2015) Synthetic antimicrobial $\beta$-peptide in dualtreatment with fluconazole or ketoconazole enhances the in vitro inhibition of planktonic and biofilm Candida albicans. J Pept Sci 21:853-861. https://doi.org/10.1002/psc.2827

35. Maurya IK, Pathak S, Sharma M et al (2011) Antifungal activity of novel synthetic peptides by accumulation of reactive oxygen species
(ROS) and disruption of cell wall against Candida albicans. Peptides 32:1732-1740. https://doi.org/10.1016/j.peptides.2011.06.003

36. Pfaller MA, Haturvedi V, Espinel-Ingroff A, et al (2002) Reference method for broth dilution antifungal susceptibility testing of yeasts; approved standard - second edition serving the world' s medical science community through voluntary consensus

37. Migoń D, Jaśkiewicz M, Neubauer D, et al (2018) Alanine scanning studies of the antimicrobial peptide Aurein 1.2. Probiotics Antimicrob Proteins. https://doi.org/10.1007/s12602-018-9501-0

38. Nilius AM (2002) Antimicrobial pharmacodynamics in theory and clinical practice

39. Diseases I (2000) Terminology relating to methods for the determination of susceptibility of bacteria to antimicrobial agents. Clin Microbiol Infect 6:503-508. https://doi.org/10.1046/ j.1469-0691.2000.00149.x

40. Sherry L, Kean R, McKloud E et al (2017) Biofilms formed by isolates from recurrent vulvovaginal candidiasis patients are heterogeneous and insensitive to fluconazole. Antimicrob Agents Chemother 61:1-4. https://doi.org/10.1128/AAC.01065-17

41. Scarsini M, Tomasinsig L, Arzese A et al (2015) Antifungal activity of cathelicidin peptides against planktonic and biofilm cultures of Candida species isolated from vaginal infections. Peptides 71:211221. https://doi.org/10.1016/j.peptides.2015.07.023

42. IRG Capoci PDS Bonfim-Mendonça GS Arita et al 2015 Propolis is an efficient fungicide and inhibitor of biofilm production by vaginal Candida albicans. Evid Based Complement Alternat Med 2015 https://doi.org/10.1155/2015/287693

43. Consolaro MEL, Albertoni TA, Svidzinski AE et al (2005) Vulvovaginal candidiasis is associated with the production of germ tubes by Candida albicans. Mycopathologia 159:501-507. https://doi.org/10.1007/s11046-005-1149-0

44. Tellapragada C, Eshwara VK, Johar R et al (2014) Antifungal susceptibility patterns, in vitro production of virulence factors, and evaluation of diagnostic modalities for the speciation of pathogenic Candida from blood stream infections and vulvovaginal candidiasis. J Pathog 2014:1-8. https://doi. org/10.1155/2014/142864

45. Dawgul M, Maciejewska M, Jaskiewicz M, et al (2014) Antimicrobial peptides as potential tool to fight bacterial biofilm. In: Acta Poloniae Pharmaceutica - Drug Research. pp 39-47

46. Venisse N, Grégoire N, Marliat M, Couet W (2008) Mechanismbased pharmacokinetic-pharmacodynamic models of in vitro fungistatic and fungicidal effects against Candida albicans. Antimicrob Agents Chemother 52:937-943. https://doi. org/10.1128/AAC.01030-07

Publisher's Note Springer Nature remains neutral with regard to jurisdictional claims in published maps and institutional affiliations. 